\title{
25 Jahre Kinderrechtskonvention - Herausforderung für die Medizinethik
}

\author{
Claudia Wiesemann
}

Online publiziert: 25. September 2014

(C) Springer-Verlag Berlin Heidelberg 2014

Am 20. November 2014 wird die UN-Kinderrechtskonvention 25 Jahre alt - ein wichtiger Anlass, darüber nachzudenken, ob Kinderrechte in der Medizin mittlerweile ausreichend Berücksichtigung finden.

Denn eine Vielzahl ethischer Probleme berührt die moralischen Interessen oder Rechte von Kindern, so in der Reproduktionsmedizin, bei der genetischen Diagnostik, bei der Forschung mit Minderjährigen, bei der Sterbehilfe, beim Enhancement, bei Schönheitsoperationen für Jugendliche, beim Umgang mit ADHS oder Intersex, bei der genitalen Verstümmelung von Mädchen oder - wie kürzlich deutlich geworden - bei der Beschneidung von Jungen. Der Gesetzgeber hat das „Wohl des Kindes“ als Ziel elterlicher Sorge (§ 1626 Bürgerliches Gesetzbuch) und als maßgebliche Orientierung des kinderbezogenen Familienrechts bestimmt. Als Rechtsgrenze gilt der Begriff der Kindeswohlgefährdung ( $\$ 1666$ BGB). Dabei geht er von einem elterlichen Primat für die Interpretation, Förderung und den Schutz der Kindesinteressen aus (Art. 6 Abs. 2 S. 1 Grundgesetz). Aber was ist unter Kindeswohl bzw. unter den Interessen des Kindes zu verstehen? Sind damit die subjektiven, an den aktuellen Empfindungen oder Wünschen des Kindes gemessenen oder die von einzelnen Eltern als angemessen bestimmten oder doch die objektiven, dem gesunden Menschenverstand als vernünftig erscheinenden Interessen des Kindes gemeint? Zudem ist zu fragen, ob die Interessen des Kindes hier und jetzt oder die Interessen des zukünftigen Erwachsenen, zu dem es sich einmal entwickeln wird, Vorrang haben sollen. Unter dem Schlagwort vom Recht des Kindes auf eine offene Zukunft wird dieses Problem gelegentlich angerissen, aber kaum in all seiner Komplexität diskutiert.

Schließlich wirft auch die Berücksichtigung des Kindeswillens bzw. der Meinung des Kindes, wie von Art. 12 der UN-Kinderrechtskonvention gefordert, eigene Fragen hinsicht-

Prof. Dr. C. Wiesemann $(\bowtie)$

Institut für Ethik und Geschichte der Medizin,

Universitätsmedizin Göttingen, Humboldtallee 36,

37073 Göttingen, Deutschland

E-Mail: cwiesem@gwdg.de 
lich des Kindeswohls auf. Denn wie verhalten sich Kindeswille und Kindeswohl zueinander? Juristen tendieren dazu, den Kindeswillen als Teil des Kindeswohls aufzufassen. Demnach hat die Nichtbeachtung des Kindeswillens einen Eingriff in das Kindeswohl zur Folge. Was aber ist zu tun, wenn Kinder oder Jugendliche, deren Selbstbestimmungsfähigkeit fraglich ist, mit Nachdruck einen Willen kundtun, der gegen ihr von Eltern und Ärzten wohlverstandenes Interesse gerichtet ist, wenn z. B. ein Jugendlicher eine lebensrettende Transplantation ablehnt? Kann, darf, muss man ihn zur Transplantation zwingen?

Kinderärztinnen und Kinderärzte, die meine Doktorandin Sabine Peters dazu befragt hat [1], empfinden ihre Rolle im Spannungsfeld von Kindesinteressen und Elterninteressen, Kindeswillen und Kindeswohl berechtigterweise als prekär. Eine Mehrheit hält es für wichtig, Kinderrechte in der Medizin stärker zu berücksichtigen. Doch es fehlt ihnen ganz offensichtlich an ausreichendem theoretischem Rüstzeug für die komplexen ethischen Probleme der Praxis. Ein wesentlicher Grund dafür ist eine Tendenz der philosophischen Ethik, Kinder betreffende Fragen als marginal zu behandeln oder gar ganz zu ignorieren. Es ist immer noch die Regel, dass Abhandlungen zu zentralen ethischen Begriffen wie Selbstbestimmung, Freiheit oder Würde die Situation von Kindern unberücksichtigt lassen, so als ob nur Erwachsene als moralische Subjekte in Frage kommen [2]. Dagegen fördert die entwicklungspsychologische Forschung mehr und mehr zu Tage, wie selbstverständlich schon Kleinkinder moralisch fühlen und handeln. Sie werden schon lange nicht mehr als jene vormoralischen Wesen angesehen, von denen Jean Piaget und Lawrence Kohlberg noch ganz selbstverständlich ausgingen.

Umso wichtiger, dass gerade die Deutsche Forschungsgemeinschaft ein von Alexander Bagattini beantragtes Netzwerk für den wissenschaftlichen Nachwuchs unter dem Titel „Kindeswohl und Kinderschutz - Normative Grundlagen des Kindeswohls“ bewilligt hat. Es braucht solche Initiativen und es braucht systematische Förderung, wenn die Ziele der UN-Kinderrechtskonvention - die immerhin den Status einer Menschenrechtserklärung hat - langfristig auch in der Medizin umgesetzt werden sollen.

\section{Literatur}

1. Peters S (2013) Wenn Kinder anderer Meinung sind. Die ethische Problematik von Kindeswohl und Kindeswille in der Kinder- und Jugendmedizin. Diss. med., Universität Göttingen. http://ediss.uni-goettingen.de/handle/11858/00-1735-0000-0001-BBDB-8. Zugegriffen: 18. Sept. 2014

2. Wiesemann C (2014) Der moralische Status des Kindes in der Medizin. In: Ach JS, Lüttenberg B, Quante M (Hrsg.) wissen.leben.ethik. Themen und Positionen der Bioethik. mentis, Münster, S 155-168. 